\title{
BRCA1 Gene Mutations and Influence of Chemotherapy on Autophagy and Apoptotic Mechanisms in Egyptian Breast Cancer Patients
}

\author{
Mohamed Ahmed Abdel-Mohsen ${ }^{1 *}$, Omiama Ali Ahmed ${ }^{1}$, Yasser Mostafa El- \\ Kerm $^{2}$
}

\begin{abstract}
Background: It is well established that mutations in the BRCA1 gene are a major risk factor for breast cancer. Induction of cancer cell death and inhibition of survival are the main principles of cancer therapy. In this context, autophagy may have dual roles in cancer, acting on the one hand as a tumor suppressor and on the other as a mechanism of cell survival that can promote the growth of established tumors. Therefore, understanding the role of autophagy in cancer treatment is critical. Moreover, defects in apoptosis, programmed cell death, may lead to increased resistance to chemotherapy. Purpose: The aim of the present study was to detect BRCA1 gene mutations in order to throw more light on their roles as risk factors for breast cancer in Egypt. Secondly the role of autophagy and apoptosis in determining response to a fluorouracil, doxorubicin, cyclophosphamide (FAC) regimen was investigated. Materials and Methods: Forty-five female breast cancer cases and thirty apparently healthy females were enrolled in the present study. Serum levels of autophagic biomarkers, Beclin 1 and LC3 as well as the serum levels of apoptosis biomarkers Bcl-2 and Caspase-3 were measured before and after chemotherapy. Results: BRCA1 mutations were found in $5(16.7 \%)$ and $44(99.8 \%)$ of the controls and cancer patients, the most frequent being 5382insC followed by C61G and 185 delAG. The results revealed that chemotherapy caused elevation in serum concentration levels of the autophagic biomarkers (Beclin 1 and LC3). This elevation was associated with a significant decrease in serum concentration levels of Bcl-2 and significant increase in caspase-3 concentration levels (apoptotic markers). Conclusions: The results of the present study indicate a very high level of BRCA mutations in breast cancer cases in Egypt and point to involvement of autophagic and apoptotic machinery activation in response to FAC chemotherapy.
\end{abstract}

Keywords: Breast cancer - BRCA1 gene mutation - autophagy - apoptosis - chemotherapy

Asian Pac J Cancer Prev, 17 (3), 1285-1292

\section{Introduction}

As the leading cause of cancer deaths among women breast cancer remains a medical and social challenge, as well as a major public health problem. On a global level, it continues to be a devastating disease (American cancer Society, 2012). It represents the most common female malignancy in both the developing and developed world. Despite well-documented reductions in mortality from breast cancer during the past two decades, incidence rates continue to increase and do so more rapidly in countries that historically had low rates (Benson and Jatoi 2012). In Egypt, and as in global figure, the incidence rates continue to increase. It has been reported that breast cancer is the most common cancer among females accounting for $37.7 \%$ of their total cancers with 12,621 new cases in 2008 (Zeeneldin et al., 2013).
Several factors may be responsible for the development of breast cancers, where they fall into modifiable and non-modifiable factors. Modifiable factors include; socioeconomic status, radiation exposure, modifiable hormonal factors such as hormone replacement therapy and lifestyle factors such as obesity and cigarette smoking. Non-modifiable risk factors include, age, reproductive factors, family history of breast disease and genetic predisposition (Lakshmi et al., 2013). However, genetic factors are thought to contribute to approximately $5 \%$ of all breast cancer cases, but to $25 \%$ of cases diagnosed before age 30 years. There are several breast cancer susceptibility genes that have been identified. These genes include in the first degree BRCA1 and BRCA2, and other tumor suppressor genes (TSGs) to a lesser extent, such as p53 (Tam 2010). Mutations of genes BRCA1 and BRCA2 involved in breast cancer susceptibility are

${ }^{I}$ Applied Medical Chemistry Department, ${ }^{2}$ Cancer Management and Research Department, Medical Research Institute, Alexandria University, Alexandria,Egypt*For correspondence: prof_abdelmohsenma@yahoo.com 
inherited in autosomal dominant fashion and associated with significant increases in the risk of breast cancer and ovarian carcinoma (Mavaddat et al., 2013). It has been reported, the existence of more than 1,200 different mutations for BRCA1, including 5382insC, 185 delAG and C61G. The first mutation is a frame shift mutation where there is an insertion of a cytosine in codon 5382 of exon 20 (5382insC). The second mutation is a frame shift mutation at position 185 in exon 2, involving deletion of adenine and guanine (185 delAG mutation), this deletion of the two base pairs results in a frame shift with the generation of a translation stop at downstream codon 64. The third mutation is a missense mutation where a substitution of conserved cysteine 61 with glycine (C61G) (Pohlreich et al., 2005).

On the other hand, understanding of the principles of tumour biology and cellular kinetics is helpful to appreciate the mechanisms of action of cancer chemotherapy. The main purpose of chemotherapy is to target proliferating cells to induce multiple effects, including apoptosis, necrosis, autophagy, mitotic catastrophe, and senescence. The cellular outcome is dependent on several factors, including the type of drug used, the concentration of drug that will reach the tumor cells, and the properties of the tumor and its microenvironment (Mansilla et al., 2012). Fluorouracil, doxorubicin, cyclophosphamide (FAC protocol) is a commonly used regimen for breast cancer due to its proven efficacy, acceptable toxicity, high affordability (Montoya et al., 2013). In the past decades several studies revealed the apoptosis induction by FAC regimen (Pan et al., 2013), as well as, recently autophagy has been extensively observed in FAC regimen treatment (Nyhan et al., 2012; Pan et al., 2013). Though induction of autophagy may lead to cell death as well as cell survival, therefore, understanding the molecular mechanisms implicated in the regulation of either cell survival or cell death will help to identify a relevant target for tumor prevention and treatment (King 2012; Ding et al., 2013).

Accordingly, the main objective of the present study was, in part, to explore BRCA1 gene mutations in order to throw more lights on its role as a risk factor of breast cancer in Egypt. Also, it is an attempt to understand the major issues surrounding the controversial role of autophagy and apoptosis in response to chemotherapy. gnancy of thact. It is the third (Järvinen et al., 1995).

\section{Materials and Methods}

\section{Subjects}

According to the instructions of the Ethics Committee of the Medical Research Institute, a signed consent was obtained from all individuals enrolled in the study and the ethical considerations were conformed. The subjects enrolled in this study were 45 breast cancer patients selected from those who were referred to Cancer Management and Research Department - Medical Research Institute - University of Alexandria, and matched apparently healthy women $(\mathrm{n}=30)$ considered as control group that was used for BRCA1 results comparison.

Inclusion criteria: i) Patients pre-operatively clinically diagnosed as breast cancer patients by clinical mammography; ultrasound; Fine Needle Aspiration Cytology (FNAC) and breast biopsy. ii) Breast cancer patients with stage (II-III) and that were subjected to surgical treatment. iii) Breast cancer patients that did not receive pre-operative neoadjuvant chemotherapy. iv) Breast cancer patients that receive the recommended adjuvant chemotherapy course consists of six cycles of 5-Flourouracil, Adriamycin, and cyclophosphamide (FAC).

Exclusion Criteria: $i$ ) Women with other types of malignancy. ii) Pregnant and lactating women. iii) Women suffering from cardiac diseases. $i v$ ) Women that receives treatment course other than the six cycles of FAC. Demographic and Clinicopathological Data collection:

A file record has been filed for each patient, which contained all the personal information, history and the clinicopathological data. The clinicopathological data included were; tumor size; tumor pathological grade; axillary lymph node involvement; vascular invasion; estrogen receptor status (ER); progesterone receptor status (PR) and Her-2 expression. Each breast cancer patient's clinical stage was determined by the oncologist according to the tumor-node-metastasis (TNM) classification system.

\section{Sampling}

Blood samples were collected (during the period between December 2012 and May 2014) from each patient in breast cancer patients group before the first cycle of chemotherapy and before the sixth cycle of the chemotherapeutic course. Blood samples were collected using aseptic precautions into two vaccutainer tubes, one containing EDTA and the other was plain for serum. Aliquots from each sample were stored at $-80 \mathrm{C}$ for further processing.

\section{BRCAl gene mutation detection}

BRCA1 gene mutation was detected by multiplex mutagenically separated polymerase chain reaction (MS - PCR) and restriction fragment length polymorphism polymerase chain reaction (PCR-RFLP) method. The BRCA1 gene mutation detection consists of DNA extraction and subsequent amplification procedures. DNA was extracted using a DNA Extraction kit (Fermentas GeneJETTM Genomic DNAPurification Kit). The quality of the extracted DNA was evaluated by $0.7 \%$ agarose gel electrophoresis and the quantity was measured by UV spectrophotometer taking optical density (OD) at 260 and $280 \mathrm{~nm}$. The 260/280 $\mathrm{nm}$ absorbance ratio ranged from 1.7 to 1.9 indicating high quality DNA.

\section{Detection of 185delAG and 5382insC BRCAl gene mutations}

DNA Amplification: Primers were designed for amplification of 185delAG and 5382insC BRCA1 gene mutations in exons 2 and 20 respectively to be suitable for PCR (Teng et al., 1996; Chan et al., 1999; El-Debaky et al., 2011).

\author{
BRCA1 185delAG (Exon 2) \\ Common forward (P1); 5'-GGTTGGCAGCAATA \\ TGTGAA
}


BRCA1 Mutations and Influence of Chemotherapy on Autophagy and Apoptosis in Egyptian Breast Cancer Patients

Wild-type reverse (P2); 5'-GCTGACTTAC CAGATG GGACTCTC

Mutant reverse (P3); 5'-CCCAAATTAA TACAC TCTTGTCG TGACTTACCAGA TGGGACAGTA

BRCA1 5382insC (Exon 20)

Common reverse (P4); 5'-GACGGGAAT CCAA ATTACACAG

Wild-type forward (P5); 5'-AAAGCGAGC AAG AGAATCGCA

Mutant forward (P6); 5'-AATCGAAGA AACC ACCAAAGTCC TTAGCGAGCAA GAGAATCACC

Amplification was carried out using Dream Taq Green PCR Master Mix (Amplification was carried out using Dream Taq green PCR master Mix (2x) purchased from Fermentas Fermentas, Germany). Each reaction mixture consisted of $12.5 \mu \mathrm{l}$ of the Taq PCR master Mix $(2 \mathrm{x}), 5 \mu \mathrm{L}$ of the template DNA and the Allele specific primers were added at $2.0 \mathrm{mmol} / \mathrm{L}$ for $\mathrm{P} 1$ and $\mathrm{P} 3 ; 0.4 \mathrm{mmol} / \mathrm{L}$ for $\mathrm{P} 2$; $0.12 \mathrm{mmol} / \mathrm{L}$ for P4, P5, and P6, then nuclease free water was added to reach a final volume of $25 \mu \mathrm{L}$. Thermal cycler was used for amplification according to the following program: an initial $2 \mathrm{~min}$ of activation at $95^{\circ} \mathrm{C}$, followed by 35 cycles of $15 \mathrm{~s}$ of denaturation at $94^{\circ} \mathrm{C}, 15 \mathrm{~s}$ of annealing at $57^{\circ} \mathrm{C}$, and $30 \mathrm{~s}$ of extension at $72^{\circ} \mathrm{C}$, and a final extension step of $5 \mathrm{~min}$ at $72^{\circ} \mathrm{C}$.

Agarose gel electrophoresis: $10 \mathrm{ml}$ of each amplified DNA and 1000 bp ladder (molecular weight marker) were separated on $2 \%$ agarose gel containing $0.3 \mathrm{mg} / \mathrm{ml}$ of ethidium bromide. The bands were visualized using UV transilluminator, photographed and analyzed (Chan et al., 1999).

\section{Detection of C61G mutation BRCA1 mutation by RFLP- PCR method}

DNA Amplification: Primers were designed for amplification of C61G BRCA1 gene mutation in exon 5 to be suitable for PCR for this gene (Grzybowska et al., 2002; El-Debaky et al., 2011). The sequence of primers were

Forward primer CTC TTA AGG GCA GTT GTG AG Reverse primer TTC CTA CTG TGG TTG CTT CC.

Amplification was carried out using Dream Taq green PCR master Mix (2x) purchased from Fermentas, Germany. The PCR mix contained $12.5 \mu \mathrm{L}$ of Taq PCR master Mix (2x); $1.25 \mu \mathrm{L}$ of each of the two primers; $5 \mu \mathrm{L}$ of the template DNA and $10 \mu \mathrm{L}$ of nuclease free water to reach a final volume of $25 \mu \mathrm{L}$. Thermal cycler was used for amplification according to the following program: initial denaturation at $95{ }^{\circ} \mathrm{C}$ for 3 mins, 35 cycles of denaturation at $95{ }^{\circ} \mathrm{C}$ for $1 \mathrm{~min}$, annealing at $56^{\circ} \mathrm{C}$ for 1 min and extension at $72{ }^{\circ} \mathrm{C}$ for 2 mins, followed by final extension at $72{ }^{\circ} \mathrm{C}$ for 10 mins then held at $4{ }^{\circ} \mathrm{C}$.

Restriction endonuclease digestion: The amplified products of exon 5 were digested by AvaII restriction endonuclease to detect C61G mutation, using Eco 471 AvaII kits according to the following protocol: Preparation of a mixture of $10 \mu \mathrm{L}$ of PCR reaction mixture, $18 \mu \mathrm{L}$ of nuclease free water, $2 \mu \mathrm{L}$ of $10 x b u f f e r ~ R$ and $4 u$ of Eco471.
The product was mixed gently and spinned down for few seconds, incubated at 37 for $15 \mathrm{~min}$. Then thermal inactivation was done at $65^{\circ} \mathrm{C}$ for $20 \mathrm{~min}$.

Agarose gel electrophoresis: After AvaII digestion gel electrophoresis of the amplified products was carried out and one band was expected to be seen if no mutation and 3 bands if heterozygous mutation was present (Grzybowska et al., 2002).

\section{Biomarkers of autophagy}

Determination of serum Beclin 1 and LC3 was carried out using Enzyme-linked immunosorbent assay (ELISA) technique kits that were purchased from Uscn Life Science Inc.

\section{Biomarkers of apoptosis}

Determination of serum Bcl-2 and Caspase-3 was carried out using Enzyme-linked immunosorbent assay (ELISA) technique kit that were purchased from eBioscience.

\section{Statistical analysis}

Statistical analysis was performed with SPSS 17.0 for Windows. The distribution of quantitative variables was tested for normality by using of a 1- sample KolmogorovSmirnov test. For comparison of the quantitative variables,

Table 1. Demographic Characteristics and Clinicopathological Characteristics of Apparently Healthy females and Breast cancer Patints

\begin{tabular}{|c|c|c|}
\hline \multicolumn{2}{|c|}{ Healthy Females (30) } & \multirow{2}{*}{$\begin{array}{l}\text { BC Patients (45) } \\
51 \pm 12\end{array}$} \\
\hline$\overline{\text { Age (Years) (Mean } \pm \text { SD) }}$ & $42 \pm 13$ & \\
\hline$<40$ years & $15(50 \%)$ & $8(17.8 \%)$ \\
\hline$\geq 40$ years & $15(50 \%)$ & $37(82.2 \%)$ \\
\hline \multicolumn{3}{|l|}{ Menopause: } \\
\hline Pre-menopause & $22(73.3 \%)$ & $19(42.2 \%)$ \\
\hline Post-menopause & $8(26.7 \%)$ & $26(57.8 \%)$ \\
\hline \multicolumn{3}{|l|}{ Family History: } \\
\hline Positive & $5(16.7 \%)$ & $12(26.7 \%)$ \\
\hline Negative & $25(83.3 \%)$ & $33(73.3 \%)$ \\
\hline \multicolumn{3}{|l|}{ Estrogen Receptor Status: } \\
\hline Positive & & $38(84.4 \%)$ \\
\hline Negative & & $07(15.6 \%)$ \\
\hline \multicolumn{3}{|c|}{ Progesterone Receptor Status: } \\
\hline Positive & & $37(82.2 \%)$ \\
\hline Negative & & $08(17.8 \%)$ \\
\hline \multicolumn{3}{|l|}{ HER2neu Status: } \\
\hline Positive & & $11(24.4 \%)$ \\
\hline Negative & & $38(75.6 \%)$ \\
\hline \multicolumn{3}{|l|}{ Lymph Node Involvement: } \\
\hline Positive & & $23(51.1 \%)$ \\
\hline Negative & & $22(48.9 \%)$ \\
\hline \multicolumn{3}{|l|}{ Vascular Invasion: } \\
\hline Positive & & $41(91.1 \%)$ \\
\hline Negative & & $4(6.7 \%)$ \\
\hline \multicolumn{3}{|l|}{ Grade: } \\
\hline II & & $37(82.2 \%)$ \\
\hline III & & $08(17.8 \%)$ \\
\hline \multicolumn{3}{|l|}{ Stage: } \\
\hline I & & $07(15.6 \%)$ \\
\hline II & & $31(68.9 \%)$ \\
\hline III & & $03(6.7 \%)$ \\
\hline IV & & $04(8.9 \%)$ \\
\hline
\end{tabular}


the paired Student's T- test and Wilcoxon signed-rank test parametric and non-parametric, respectively, were used to compare the mean levels before and after chemotherapy. A $\chi 2$ test was used to compare qualitative variables. Generally, (p) values $<0.05$ were considered to indicate a statistically significant difference.

\section{Results}

Demographic characteristics and clinicopathological features of breast cancer patients are summarized in Table 1.

Three mutations in BRCA1 gene were analyzed in the

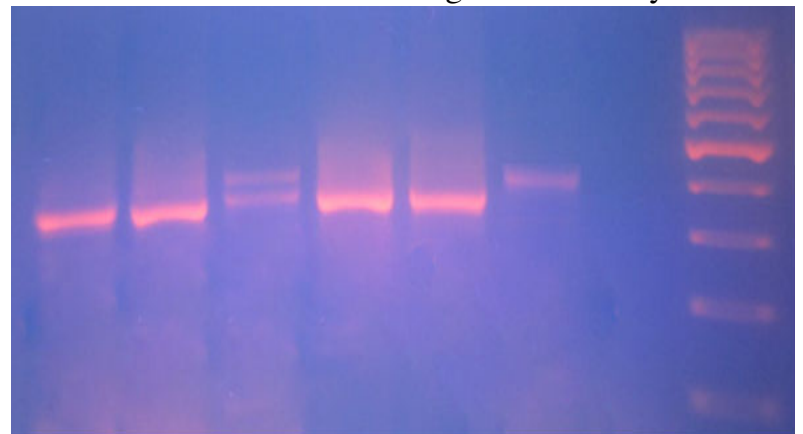

Figure 1. Gel Eletrophoresis of Amplified Products of BRCA1 Gene of Exon 2 (BRCA1 185delAG). Lane 1, 2, 4 and 5 Showing Wild Type Sample. Lane 3 Shoeing Heterozygous Mutation. Lane 6 Showing Homozygous Mutation. Lane 7 Showing Negative Apparently Healthy Subject. Lane 8 Show DNA Ledder $1000 \mathrm{pb}$

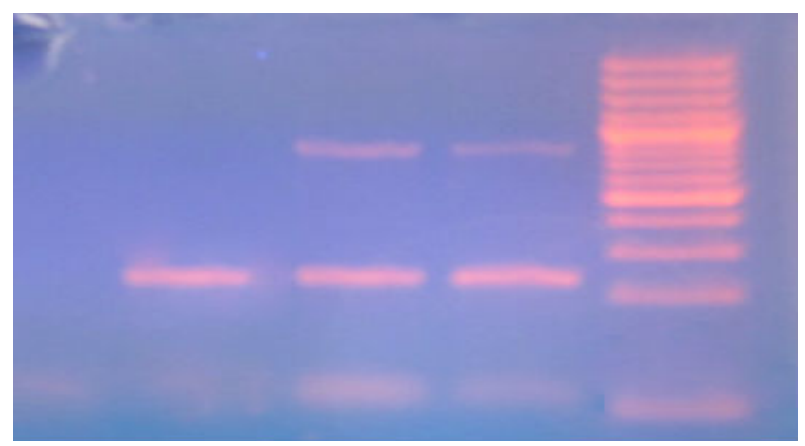

Figure 2. Gel Electrophoresis of the Amplified Products of BRCA1 Gene of Exon 5 (BRCA1C61G). Lane 1 Shows the Amplified Products before Avall Digestion. Lane 2\&3 Show Three Bands Indication Heterozygous Mutation. Lane 4 Shows DNA Ladder 3000 bp

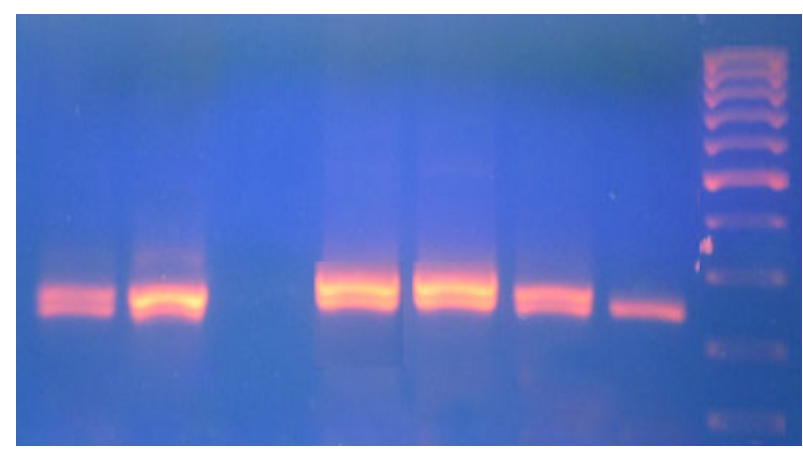

Figure 3. Gel Electrophoresis of the Amplified Products of BRCA1 Gene of Exon 20 (BRCA15382). Lane 1,6 Show Heterozygous Mutation. Lane 2, 4, 5 Show Heterozygous Mutation. Lane 7 Shows Wild-Type Sample. Lane 8 Shows $100 \mathrm{bp}$ present study including 185delAG, C61G and 5382insC mutations in exons 2, 5 and 20 respectively (Figures. 1-3). It was found that $97.8 \%$ of breast cancer patients have mutations in BRCA1 gene. Meanwhile, the results showed that $16.7 \%$ of apparently healthy females only have mutations in this gene, with relative risk $(\mathrm{RR}=23.4$; $\mathrm{CI}=3.4-160 ; \mathrm{p}=0.001)$, Tables 2 . The results also showed that 5382insC, C61G and 185 delAG mutations were significantly associated with relative risk for developing breast cancer.

In respect to autophagy markers, serum Beclin 1 and LC3 concentration levels in breast cancer patients were significantly elevated after chemotherapy (Figure 4).

For apoptotic markers, while the concentration level of serum Bcl-2 in breast cancer patients was significantly reduced after chemotherapy and the concentration level of serum Caspase-3 was significantly elevated (Figure 4).

The results of the association between autophagy biomarkers and BRCA1 mutation (Table 3) showed significant decrease in serum LC3 level in patients with

Table 2. Frequencies and Relative Risk Analysis of BRCA1 Gene Exon Mutations Associated with Breast Cancer

\begin{tabular}{|c|c|c|c|c|c|}
\hline & $\begin{array}{l}\text { Healthy } \\
\text { Females (30) }\end{array}$ & $\begin{array}{c}\text { BC Patients } \\
\text { (45) }\end{array}$ & RR & $\mathrm{CI}$ & $\mathrm{p}$ \\
\hline \multicolumn{6}{|c|}{ BRCA1 Mutation } \\
\hline No & 5 & 44 & \multirow[t]{2}{*}{23.4} & \multirow[t]{2}{*}{$3.4-159.9$} & \multirow[t]{2}{*}{$0.001 *$} \\
\hline$\%$ & $16.7 \%$ & $97.8 \%$ & & & \\
\hline \multicolumn{6}{|c|}{ 5382insC (Exon 20) Mutation } \\
\hline No & 3 & 30 & \multirow[t]{2}{*}{2.6} & \multirow[t]{2}{*}{$1.7-3.9$} & \multirow[t]{2}{*}{$0.001 *$} \\
\hline$\%$ & $10.0 \%$ & $66.7 \%$ & & & \\
\hline \multicolumn{6}{|c|}{ C61G (Exon 5) Mutation } \\
\hline No & 2 & 26 & \multirow[t]{2}{*}{2.3} & \multirow[t]{2}{*}{$1.6-3.3$} & \multirow[t]{2}{*}{$0.001 *$} \\
\hline$\%$ & $6.7 \%$ & $57.8 \%$ & & & \\
\hline \multicolumn{6}{|c|}{ 185delAG (Exon 2) Mutation } \\
\hline No & 0 & 7 & \multirow[t]{2}{*}{1.8} & \multirow[t]{2}{*}{$1.5-2.2$} & \multirow[t]{2}{*}{$0.020^{*}$} \\
\hline$\%$ & $0.0 \%$ & $15.6 \%$ & & & \\
\hline
\end{tabular}

* Significance was considered significant at $\mathrm{p}<0.05$; RR: Relative Risk; CI: Confedence Interval

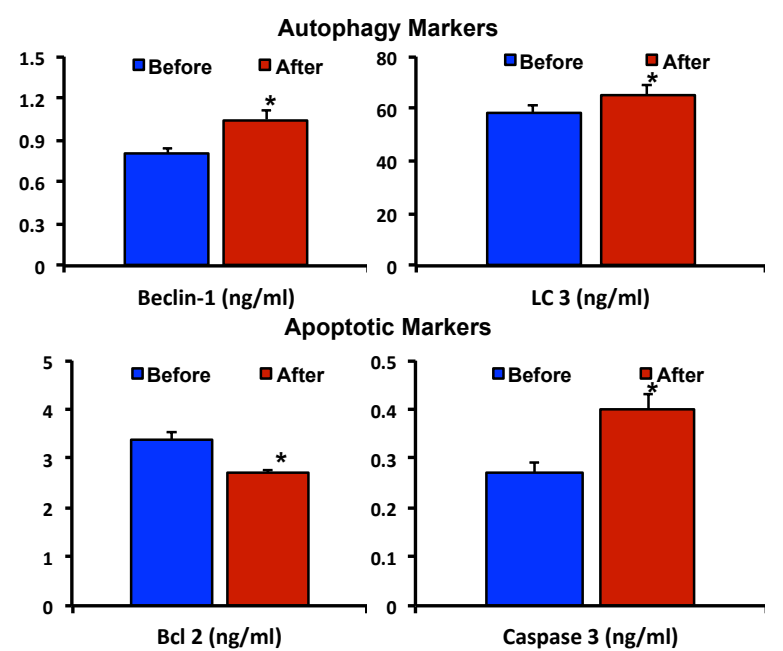

Figure 4. Mean Serum Concentration Levels of Autophagy Marker, Beclin 1 and LC3, and Apoptotic Markers, Bcl-2 and Caspase-3, in Breast Cancer Patients Before and After Chemotherapy *Statistically Significant, $p<0.05$ 
BRCA1 Mutations and Influence of Chemotherapy on Autophagy and Apoptosis in Egyptian Breast Cancer Patients Table 3. Association between BARCA1 A Gene Mutations and Mean Concentration Levels of Autophagy Markers and Apoptotic Markers in Breast Cancer

\begin{tabular}{|c|c|c|c|c|c|}
\hline & & Non-Mutants & Mutant & Non-Mutant & Mutant \\
\hline & & \multicolumn{4}{|c|}{ Markers of Autophagy (ng/ml) } \\
\hline & & \multicolumn{2}{|c|}{ Beclin-1 } & \multicolumn{2}{|c|}{ LC 3} \\
\hline \multirow[t]{4}{*}{ 5382insC (Exon 20) Mutation } & Number & 15 & 30 & 15 & 30 \\
\hline & Mean \pm S.E & $0.88 \pm 0.10$ & $0.76 \pm .06$ & $66.85 \pm 4.11$ & $54.26 \pm 3.10$ \\
\hline & Min-Max & $0.37-1.71$ & $0.17-1.31$ & $30.73-87.61$ & $31.88-87.72$ \\
\hline & $\mathrm{p}$ value & 0.37 & & $0.03 *$ & \\
\hline \multirow[t]{4}{*}{ C61G (Exon 5) Mutation } & Number & 19 & 26 & 19 & 26 \\
\hline & Mean \pm S.E & $0.83 \pm 0.08$ & $0.78 \pm 0.07$ & $53.13 \pm 4.15$ & $62.35 \pm 3.21$ \\
\hline & Min-Max & $0.17-1.44$ & $0.28-1.71$ & $31.88-87.72$ & $30.73-87.61$ \\
\hline & $\mathrm{p}$ value & 0.56 & & 0.09 & \\
\hline \multirow[t]{6}{*}{ 185delAG (Exon 2) Mutation } & Number & 38 & 7 & 38 & 7 \\
\hline & Mean \pm S.E & $0.81 \pm 0.05$ & $0.75 \pm 0.15$ & $59.12 \pm 2.79$ & $54.84 \pm 7.66$ \\
\hline & Min-Max & 0.17-1.71 & $0.36-1.44$ & $30.73-87.72$ & $31.88-84.06$ \\
\hline & $\mathrm{p}$ value & 0.59 & & 0.51 & \\
\hline & & \multicolumn{4}{|c|}{ Markers of Apoptosis (ng/ml) } \\
\hline & & \multicolumn{2}{|c|}{$\mathrm{Bcl}-2$} & \multicolumn{2}{|c|}{ Caspase- 3} \\
\hline \multirow[t]{4}{*}{ 5382insC (Exon 20) Mutation } & Number & 15 & 30 & 15 & 30 \\
\hline & Mean \pm S.E & $3.80 \pm 0.30$ & $3.12 \pm 0.16$ & $0.22 \pm .028$ & $0.29 \pm .027$ \\
\hline & Min-Max & $2.31-5.67$ & $2.19-5.20$ & $0.10-0.47$ & $0.09-0.61$ \\
\hline & $\mathrm{p}$ value & $0.04 *$ & & 0.07 & \\
\hline \multirow[t]{4}{*}{ C61G (Exon 5) Mutation } & Number & 19 & 26 & 19 & 26 \\
\hline & Mean \pm S.E & $3.21 \pm 0.23$ & $3.45 \pm 0.21$ & $0.24 \pm 0.03$ & $0.29 \pm 0.03$ \\
\hline & Min-Max & $2.25-5.46$ & $2.19-5.67$ & $0.10-0.49$ & $0.09-0.61$ \\
\hline & $\mathrm{p}$ value & 0.37 & & 0.41 & \\
\hline \multirow[t]{4}{*}{ 185delAG (Exon 2) Mutation } & Number & 38 & 7 & 38 & 7 \\
\hline & Mean \pm S.E & $3.41 \pm 0.16$ & $3.02 \pm 0.42$ & $0.27 \pm 0.02$ & $0.27 \pm 0.06$ \\
\hline & Min-Max & $2.19-5.67$ & $2.25-5.46$ & $0.09-0.58$ & $0.10-0.61$ \\
\hline & $\mathrm{p}$ value & 0.23 & & 0.94 & \\
\hline
\end{tabular}

* Significance was considered to be $\mathrm{p}<0.05$

5382insC BRCA1 mutation. While the results of the association between apoptosis biomarkers and BRCA1 mutation (Table 3) showed significant decrease in serum Bcl-2 level in patients with 5382insC BRCA1 mutation.

\section{Discussion}

Several studies investigated the frequency of BRCA1 mutation in breast cancer patients. In Egypt, El-Debaky et al., (2011), have reported that $86.7 \%$ of breast cancer patients and $55 \%$ of apparently healthy females have the three forms of BRCA1 mutations, respectively. In a similar manner the results of the present study showed that $97.8 \%$ of breast cancer patients and $16.7 \%$ of apparently healthy females have the three forms of BRCA1 mutations. Based on the results of El-Debaky et al., (2011) and the results of present study, it could be concluded that the frequency of the three forms of BRCA1 mutations in breast cancer patients is higher than that in apparently healthy females in Egypt. Also, the results of the present study revealed that females having BRCA1 mutation has a 23 folds increased risk for the development of breast cancer compared to females without BRCA1 mutation. This in turn, may lead to the suggestion that BRCA1 gene mutation may be a potential risk factor of breast cancer in Egypt.

Meanwhile, several studies investigated the genotype frequency and reported that the frequency of BRCA1 5382insC is much higher in breast cancer patients (Grzybowska et al., 2002; El-Debaky et al., 2011; Dillenburg et al., 2012; Burcoæ et al., 2013; Ashton-
Prolla and Vargas 2014; Bensam et al., 2014). In Egypt, El-Debaky et al., (2011), reported that the frequency of the 5382insC; C61G; and 185 delAG mutations were $56 \%$; $40 \%$; and 22\%, respectively. Also, in Egypt, Bensam et al., (2014), showed that the frequency of 185 delAG mutations was $(15 \%)$ showing the similarity to the present study.

In addition, the BRCA1 5382insC mutation (more recently described as c.5266dup) is the second most frequent mutation described in this gene worldwide, according to the Breast Cancer Information Core (BIC, http://www.research. nhgri.nih.gov/bic/). The high prevalence of 5382insC mutation was described initially in Ashkenazi Jews, and this mutation has subsequently been described in other populations from Central and Eastern Europe (Ashton-Prolla and Vargas 2014). In agreement with all of the previously mentioned studies, the results of the present study revealed that the 5382insC mutation was the most frequent BRCA1 mutation among both the breast cancer patients and the apparently healthy females (44\%), followed by C61G mutation (37.3\%) and 185 delAG mutation $(9.3 \%)$. The relative risk for breast cancer in women having 5382insC; C61G and 185 delAG forms of BRCA1 gene mutation, are 2.6; 2.3 and 1.8, respectively. Accordingly, these results may reflect more, the involvement of BRCA1 gene mutations in development of breast cancer in Egypt. Since the risk of breast cancer increases steadily with age (McGuire et al., 2015), in the present study the relative risk estimation revealed that the females with BRCA1 mutation and with age more than 40 years has 1.3 folds increased risk for the 
development of breast cancer compared to females with age less than 40 years.

Beclin 1 is an essential modifier of the autophagic process and has been implicated in the tumorigenesis of many types of cancers. LC3 is a specific marker of autophagosome formation and is the most widely monitored autophagy-related protein (Choi et al; 2014). However, there are a limited number of studies of autophagy markers in breast cancer and most of them regarding autophagy and breast cancer are carried out on cell lines, in vitro (Marquez and Xu 2012; Pan et al., 2013). In addition, according to our knowledge, there are few studies that investigated autophagy-related proteins in serum of breast cancer patients. The expression of autophagy-related proteins LC3 and Beclin 1 has been reported to be a prognostic factor in various human cancers, but the results are conflicting (Choi et al., 2014).

The results of the present study showed significant increase in both serum Beclin 1 and LC3 levels in breast cancer patients after chemotherapy. Pan et al., (2013), have reported that Beclin 1 was significantly increased after 5-FU treatment in lung cancer cells. In agreement with the results of the present study, Marquez and $\mathrm{Xu}$, (2012), reported that overexpression of Beclin 1 caused by the treatment of doxorubicin which increases autophagic cell death.

Several studies have reported the overexpression of autophagy markers, Beclin 1 and LC3, as a result of treatment of different therapeutic agents. In their study on glioma cells U251-MG, Gao et al., (2009) have reported the up-regulation of LC3 and beclin1 expression in these cells due to treatment with therapeutic agent. Also, Park et al., (2013) have reported the overexpression of Beclin 1 and LC3 in colon cancer patients on 5-fluororuacilbased adjuvant therapy. While the approach is different, the results of the present study are in agreement with the results of the previous studies.

In the light of the results of the present study, it could be argued that the treatment with FAC trigger autophagy machinery as indicated by the significant increase in Beclin1 and LC3 serum concentration levels after chemotherapy. However, triggering autophagy machinery will lead either to cell death or cell survival in a matter of consideration in future researches.

Regarding the association between the BRCA1associated carcinoma and autophagy the association in this study revealed a significant decreased level of serum LC3 in patients with 5382insC BRCA1 mutation. In contrast, Salem et al., (2013) showed that human hTERTimmortalized fibroblasts displayed an increase in the autophagy marker LC3. Also, other studies revealed that loss of BRCA1 results in the induction of autophagy (Noor 2011), that might be as a cytoprotective or executioner mechanism. These findings highlight the involvement of BRCA1 in protective autophagy induction, which may make its essential contribution to tumorigenesis and prognosis (Noor 2011; Tang et al., 2014).

Bcl-2 is a protein that has the capability to block most pro-apoptotic stimuli and therefore promotes cell survival (Ebied et al., 2013). Bcl-2 regulates the intrinsic mitochondrial apoptotic pathway that responds to numerous stress stimuli such as DNA damage or deprivation of growth factors. It maintains the integrity of mitochondria by preventing proapoptotic proteins such as Bax or Bak from initiating this pathway (Ebied et al., 2013). In breast cancer, the expression of Bcl-2 has been associated with the presence of markers of differentiation and with a longer survival in node-negative or nodepositive patients (Hammoud et al., 2014). Caspase- 3 plays a key role in both the death receptor pathway, initiated by Caspase-8. Several studies have shown that Caspase-3 activation is required for apoptosis induction in response to chemotherapeutic drugs e.g., Taxanes, 5-fluorouracil, and doxorubicin (Bellarosa et al., 2001). However, little work has been made to evaluate levels of Caspases in serum of patients under treatment (Hammoud et al., 2014).

The results of the present study revealed that the level of serum Bcl-2 concentration after chemotherapy was significantly decreased compared to its level before chemotherapy. Ebied et al., (2013) reported a significant decrease level after chemotherapy compared with its level one month after surgery. Tacar et al.,(2013), conducted a study involving doxorubicin (Adriamycin) - treated breast cancer MCF-7 cells that have shown a decrease in Bcl-2 suggesting that this decrease was expected if doxorubicin is to induce apoptosis. When doxorubicin is administered, increase in ROS stimulates 553 activation, suggesting that doxorubicin-induced $\mathrm{Bcl}-2$ down regulation is mediated by the p53 pathway. Also, p53 induces a translocation of Bax to the mitochondria where the ratio shift occurs. As the level of Bax rises and Bcl-2 is downregulated, cytochrome $\mathrm{c}$ is released from the mitochondria, leading ultimately to apoptosis (Tacar et al., 2013). In agreement with the previous studies, these results may conclude that chemotherapy induce apoptosis by decreasing Bcl-2 levels. Thus, the reduced serum Bcl- 2 concentration level could be attributed to doxorubicin administration.

The results of the present study demonstrated that the level of serum caspase- 3 after chemotherapy significantly increased compared to its level before chemotherapy. Hammoud et al., (2014), evaluated caspase-3 level in serum of patients with locally advanced and metastatic breast cancer, treated with the combination of Docetaxel and Doxorubicin, where the caspase-3 level was significantly increased in serum after chemotherapy. Elevation of caspase 3 serum level could be attributed to decrease in tumour volume and consequently apoptotic proteins in responders, however, low level of caspases after the first cycle accompanied with lower levels over time revealed a non-responsive disease (Hammound et al., 2014). Thus, the results of the present study may demonstrate activation of the apoptotic pathway. This activation may be indicated by the down-regulation of serum Bcl-2, anti-apoptotic factor, and elevation in serum Caspase-3, proapoptotic factor.

Although apoptosis and autophagy pathways utilize fundamentally distinct machinery, they are highly interconnected and share many key regulators. The crosstalk between apoptosis and autophagy is complex, as autophagy can function to promote cell survival or cell death under various cellular conditions (Young et al., 2013). While, the suppression of apoptosis is linked 
BRCA1 Mutations and Influence of Chemotherapy on Autophagy and Apoptosis in Egyptian Breast Cancer Patients

to the induction of autophagy (Selimovic et al., 2013; Zhao et al., 2013), the inhibition of autophagy can cause apoptosis (Ding et al., 2012; Selimovic et al., 2013; Zhao et al., 2013). The molecular mechanisms of crosstalk are beginning to be elucidated and have critical implications for the treatment of various diseases, such as cancer. Thus, identifying the mechanisms thought to be involved in the regulation of the crosstalk between apoptosisand autophagy-associated cell deaths is considered an important step for the development of optimal chemotherapeutic approaches for tumor treatment (Su et al., 2013). Also, it is reasonable to propose that modulation of autophagic cell death may be used as a therapeutic strategy for cancer treatment (Jain et al., 2011). Regarding autophagy and apoptosis, the expression levels of Beclin 1 and Bcl-2 are key determinants as to whether cells are resistant to apoptosis or autophagy during tumorigenesis and chemotherapy (Marquez and Xu, 2012).

Antiapoptotic Bcl-2 family proteins, which downregulate apoptosis (i.e., Bcl-2) by antagonizing the activity of proapoptotic proteins, can downregulate autophagy. Beclin 1 interacts with antiapoptotic Bcl-2 family members including Bcl-2 and Bcl-X. Binding of these Bcl-2 family proteins to Beclin 1 inhibits autophagy by preventing the association of Beclin 1 with the class III PI3K complex (Jain et al., 2013; Ryter et al., 2014) and hence prevents autophagy vesicle membrane nucleation (Jain et al., 2013).

The association between the BRCA1-associated carcinoma and apoptosis biomarkers was also investigated in this study, which revealed a significant decreased level of serum Bcl-2 in patients with 5382insC BRCA1 mutation. The results is in agreement with a study conducted by Freneaux et al., (2000), that assessed the expression of the Bcl-2 in BRCA1- associated breast carcinomas and showed a low expression of $\mathrm{Bcl}-2$ in most BRCA1-associated breast carcinomas, suggesting that BRCA1-associated breast carcinomas are characterized by high mitotic and apoptotic rates.

Autophagy has recently been linked to cell death and apoptosis is no longer considered the sole means of programmed cell death via self-elimination. The cell's decision as to which death pathway to trigger depends on many scenarios from the cellular environment to surrounding stimuli (Tacar et al., 2013). Studies that revealed that both apoptosis and autophagy share common molecular regulators, suggests that they are not exclusive pathways and that they tend to counteract one another (Tacar et al., 2013). Suppression of apoptosis is a hallmark of human cancer, as well as the desired end point of many targeted therapies is the induction of tumour cell death through apoptosis (Ward et el., 2008). Thus, mechanism-based therapies under clinical evaluation in oncology may directly induce apoptosis by targeting molecular components of apoptosis regulatory pathways (Taylor et al., 2006; Ward et al., 2008), or do so indirectly, following drug target modulation that is then coupled to apoptosis. Either way, application of informative, validated biomarkers of apoptosis in clinical trials of anticancer therapies is urgently required (Taylor et al., 2006).

In conclusion, although the relationship between autophagy and cell death is very complicated and has not been characterized in detail, it is important to understand the interaction between the two types of cell death pathways and the interplay between the core proteins in both pathway (El-Khattouti et al., 2013). Thus, the molecular mechanisms that control this relationship are considered to be a relevant target for the development of future therapeutic strategy for tumor treatment.

\section{References}

American Cancer Society (2012). Facts and Figures 2012. Atlanta. American Cancer Society

Ashton-Prolla P, Vargas FR (2014). Prevalence and impact of founder mutations in hereditary breast cancer in Latin America. Genetics and Molecular biology, 37, 234-40.

Bellarosa D, Ciucci A, Bullo A, et al (2001). Apoptotic events in a human ovarian cancer cell line exposed to anthracyclines. $J$ Pharmacology and Experimental Therapeutics, 296, 276-83.

Bensam M, Hafez E, Awad D, El-Saadani M, Balbaa M.(2014). Detection of new point mutations of BRCA1 and BRCA2 in breast cancer patients. Biochemical Genetics, 52, 15-28.

Benson JR, Jatoi I (2012). The global breast cancer burden. Future Oncology, 8, 697-702.

Burcoæ T, Cimponeriu D, Ion DA, et al (2013). Analysis of several BRCA1 and BRCA2 mutations in a hospital-based series of unselected breast cancer cases. Chirurgia (Bucur), 108, 468-72.

Chan PC, Wong BY, Ozcelik H, Cole DE (1999). Simple and rapid detection of BRCA1 and BRCA2 mutations by multiplex mutagenically separated PCR. Clinical Chemistry, 25, 1285-87.

Choi JH, Cho YS, Ko YH, et al (2014). Absence of autophagyrelated proteins expression is associated with poor prognosis in patients with colorectal adenocarcinoma. Gastroenterology Research and Practice, 2014.

Dillenburg CV, Bandeira IC, Tubino TV, et al (2012). Prevalence of 185delAG and 5382insC mutations in BRCA1, and 6174delT in BRCA2 in women of Ashkenazi Jewish origin in southern Brazil. Genetics and Molecular Biology, 35, 599-602.

Ding F, Shao ZW, Xiong LM (2013). Cell death in intervertebral disc degeneration. Apoptosis, 18, 777-85.

Ding WX, Chen X, Yin XM (2012). Tumor cells can evade dependence on autophagy through adaptation. Biochemical and Biophysical Research Community, 425, 684-8.

Ebied SA, El-Moneim NA, Hewala TI, Anwar MM, Rabi SM (2013). The diagnostic, prognostic and follow-up value of serum Bcl-2, Bax and $\mathrm{p} 53$ proteins in breast cancer patients: a comparison with serum CA 15-3. Middle East J Cancer, 4, 51-62.

El-Debaky FE, Azab NI, Alhusseini NF , Eliwa SK, Musalam HR (2011). Breast cancer gene 1 (Brca 1) mutation in female patients with or without family history in Qalubia governorate. J Am Sci, 7, 82-93.

El-Khattouti A, Selimovic D, Haikel Y, Hassan M (2013). Crosstalk between apoptosis and autophagy: molecular mechanisms and therapeutic strategies in Cancer. $J$ Cell Death, 6, 37-55.

Freneaux P, Stoppa-Lyonnet D, Mouret E, et al (2000). Low expression of bcl-2 in Brca1-associated breast cancers. $\mathrm{Br}$ J Cancer, 83, 1318-22.

Gao S, Yang XJ, Zhang WG, Ji YW, Pan Q (2009). Mechanism of thalidomide to enhance cytotoxicity of temozolomide in U251-MG glioma cells in vitro. Chinese Medical Journal, 122, 1260-6. 


\section{Mohamed Ahmed Abdel-Mohsen et al}

Grzybowska E, Siemińska M, Zientek H, Kalinowska E, Michalska J, Utracka-Hutka B, Rogozińska-Szczepka J, Kaźmierczak-Maciejewska M (2002). Germline mutations in the BRCA1 gene predisposing to breast and ovarian cancers in Upper Silesia population. Acta Biochimica Polonica, 49, 351-6.

Hammoud H, Saleh J, Bachour M, Salamoon M (2014). Serum caspase- 3 and caspase- 7 as predictive factors of response in locally advanced and metastatic breast carcinoma. Journal of Cancer Therapy, 5, 584-90

Jain K, Paranandi KS, Sridharan S, Basu A (2013). Autophagy in breast cancer and its implications for therapy. American Journal of Cancer Research, 3, 251-65.

King JS (2012). Mechanical stress meets autophagy: potential implications for physiology and pathology. Trends in Molecular Medicine, 18, 583-8.

Lakshmi R, Vijayalakshmi S, Raju A, Joy TM (2013). Assessment of various risk factors of breast cancer. International Journal of Pharmacy and Pharmaceutical Sciences, 5, 675-8.

Liang XH, Jackson S, Seaman M, et al (1999). Induction of autophagy and inhibition of tumorigenesis by beclin 1 . Nature, 402, 672-6.

Mansilla S, Llovera L, Portugal J (2012). Chemotherapeutic targeting of cell death pathways. Anticancer Agents in Medicinal Chemistry, 12, 226-38.

Marquez RT, Xu L (2012). Bcl-2: Beclin 1 complex: multiple, mechanisms regulating autophagy/apoptosis toggle switch. American J Cancer Res, 2, 214-21.

Mavaddat N, Peock S, Frost D, et al., (2013). Cancer risks for BRCA1 and BRCA2 mutation carriers: results from prospective analysis of EMBRAC. J National Cancer Institute, 105, 812-22

McGuire A, Brown JA, Malone C, McLaughlin R, Kerin MJ (2015). Effects of age on the detection and management of breast cancer. Cancers (Basel), 7, 908-29.

Montoya JE, Luna HG, Morelos AB, et al (2013). Association of creatinine clearance with neutropenia in breast cancer patients undergoing chemotherapy with fluorouracil, doxorubicin, and cyclophosphamide (FAC). Medical Journal of Malaysia, $\mathbf{6 8}, 153$.

Noor S (2011). Loss of BRCA1 in normal human mammary epithelial cells induces a novel mechanism of senescence, university of toronto. department of medical biophysics, doctoral dissertation.

Nyhan MJ, O'Donovan TR, Elzinga B, et al (2012). The BH3 mimetic HA14-1 enhances 5-fluorouracil-induced autophagy and type II cell death in oesophageal cancer cells. $\mathrm{Br} J$ Cancer, 106, 711-8.

Pan X, Zhang X, Sun H, et al (2013). Autophagy inhibition promotes 5-fluorouraci-induced apoptosis by stimulating ROS formation in human non-small cell lung cancer A549 cells. PloS one, $8,56679$.

Park JM, Huang S, Wu TT, Foster NR, Sinicrope FA (2013). Prognostic impact of Beclin 1, p62/sequestosome 1 and LC3 protein expression in colon carcinomas from patients receiving 5-fluorouracil as adjuvant chemotherapy. Cancer Biology and Therapy, 14, 100-7.

Pohlreich P, Zikan M, Stribrna J, et al (2005). High proportion of recurrent germline mutations in the BRCA1 gene in breast and ovarian cancer patients from the Prague area. Breast Cancer Research, 7, 728.

Ryter SW, Mizumura K, Choi AM (2014). The impact of autophagy on cell death modalities. Intern J Cell Biol, 2014, 502676.

Salem AF, Howell A, Sartini M, Sotgia F, Lisanti MP (2012). Downregulation of stromal BRCA1 drives breast cancer tumor growth via upregulation of HIF-1 $\alpha$, autophagy and ketone body production. Cell Cycle, 11, 4167-73.

Selimovic D, Porzig BB, El-Khattouti A, et al (2013). Bortezomib/proteasome inhibitor triggers both apoptosis and autophagy-dependent pathways in melanoma cells. Cell Signal, 25, 308-18.

Su M, Mei Y, Sinha S (2013). Role of the crosstalk between autophagy and apoptosis in cancer. J Oncol, 2013, 1-14.

Tacar O, Dass CR (2013). Doxorubicin induced death in tumour cells and cardiomyocytes: is autophagy the key to improving future clinical outcomes?. J Pharmacy and Pharmacol, 65, 1577-89.

Tam CY (2010). Lifestyle and risk factors for breast cancer in postmenopausal caucasian and chinese-canadian women. university of toronto, medical science department, doctoral thesis.

Tang MK, Kwong A, Tam KF, et al (2014). BRCA1 deficiency induces protective autophagy to mitigate stress and provides a mechanism for BRCA1 haploinsufficiency in tumorigenesis. Cancer letters, 346, 139-47.

Taylor K, Micha D, Ranson M, Dive C (2006). Recent advances in targeting regulators of apoptosis in cancer cells for therapeutic gain. Expert Opinion on Investigational Drugs, 15, 669-90.

Teng DHR, Bogden R, Mitchell J, et al (1996). Low incidence of BRCA2 mutations in breast carcinoma and other cancers. Nature Genetics, 13, 241-4.

Ward H, Cummings J, Dean E, et al (2008). Biomarkers of apoptosis. Br J Cancer, 99, 841-6.

Young MM, Kester M, Wang HG (2013). Sphingolipids: Regulators of crosstalk between apoptosis and autophagy. Journal of Lipid Research, 54, 5-19.

Zeeneldin AA, Ramadan M, Gaber AA, Taha FM (2013). Clinico-pathological features of breast carcinoma in elderly Egyptian patients: A comparison with the non-elderly using population-based data. Journal of the Egyptian National Cancer Institute, 25, 5-11.

Zhao C, Yin S, Dong Y, et al (2013). Autophagy-dependent EIF2AK3 activation compromises ursolic acid-induced apoptosis through upregulation of MCL1 in MCF-7 human breast cancer cells. Autophagy, 9, 196-207. 